\title{
Progression of myeloproliferative neoplasms to myelofibrosis and acute leukaemia
}

\author{
Hans Kreipe • Kais Hussein • Gudrun Göhring • \\ Brigitte Schlegelberger
}

Received: 10 May 2011 / Accepted: 12 May 2011 / Published online: 28 May 2011

(C) Springer-Verlag 2011

\begin{abstract}
Bcr-abl-negative myeloproliferative neoplasms (MPN), comprising polycythaemia vera (PV), primary myelofibrosis (PMF) and essential thrombocythaemia (ET), usually follow a biphasic course. From a phase which is characterized by excess production of mature haematopoietic cells of one or more lineages, many, but not all MPN, progress to haematopoietic insufficiency with cytopenia affecting two or three lineages. The latter may be the result of either fibrosis, blastic transformation or both. An intermediate stage of variable duration is called acceleration. Unlike bcr-abl-positive chronic myeloid leukaemia (CML), acceleration in MPN is not homogeneously defined. Long-lasting PV may progress to a PMF-like myelofibrosis, labelled spent phase. Less frequently, PV develops into a myelodysplastic/myeloproliferative neoplasm (MDS/MPN) resembling either atypical CML or chronic myelomonocytic leukaemia. Progression in PMF and ET leads either to advanced osteomyelofibrosis or to MDS/MPN with fibrosis. CML and bcr-abl-negative MPN share the same definition for transformation with $\geq 20 \%$ blasts in the blood or bone marrow. Transformation to blast crisis can occur at any stage in MPN and is more likely in PMF and PV than ET. There are different molecular pathways to progression. In a subset of MPN, transforma-
\end{abstract}

H. Kreipe $(\bowtie) \cdot$ K. Hussein

Institute of Pathology, Medizinische Hochschule,

Carl Neuberg Str. 1,

30625 Hannover, Germany

e-mail: Kreipe.Hans@MH-Hannover.De

G. Göhring • B. Schlegelberger

Institute of Cellular and Molecular Pathology,

Medizinische Hochschule,

Hannover, Germany tion is accompanied by the occurrence of a complex karyotype.

Keywords Progression - Myeloproliferative neoplasm . Polycythaemia vera Essential thrombocythaemia . Primary myelofibrosis

\section{Introduction}

The myeloproliferative neoplasms (MPN) according to the WHO classification comprise eight different entities, which are summarized in Table 1 [1]. Besides bcr-abl-positive chronic myeloid leukaemia (CML), the most frequent diagnoses are polycythaemia vera (PV), essential thrombocythaemia (ET) and primary myelofibrosis (PMF). All four entities have in common the fact that they may progress from a phase which is characterized by excess production of mature haematopoietic cells of one or more lineages, to haematopoietic insufficiency with cytopenia affecting two or three lineages. The transition from overproduction of blood cells to haematopoeitic insufficiency is called progression, and it is caused by different underlying biological processes. One mechanism is that neoplastic hyperproliferation with maintained capacity to differentiate is followed by loss of differentiation during blast transformation. The second mechanism, which may be combined with the first, is progressive fibrotic obliteration of the bone marrow. Progression is intrinsic to CML, PV, PMF and ET, but the likelihood and the type of progression differ between the four MPN subtypes. The propensity for blastic transformation is highest in CML and lowest in ET, whereas the probability of fibrosis is high in PMF and low in ET and CML [1,2].

Progression usually occurs in two steps with different clinical manifestations, which in CML have been labelled 
Table 1 Myeloproliferative neoplasms (according to WHO [1])

- Chronic myelogenous leukaemia, BCR-ABL1-positive

- Chronic neutrophilic leukaemia

- Polycythaemia vera

- Primary myelofibrosis

- Essential thrombocythaemia

- Chronic eosinophilic leukaemia, not otherwise specified

- Mastocytosis

- Myeloproliferative neoplasms, unclassifiable

acceleration and transformation. There is the same definition for transformation in bcr-abl-negative MPN $(\geq 20 \%$ blasts in the blood or bone marrow, extramedullary blast infiltrates), but acceleration in these diseases is not homogeneously defined. In CML, acceleration is characterized by resistance to therapy, thrombocytopenia, blood basophilia or blast increase in the marrow between $10 \%$ and $20 \%$. Bone marrow fibrosis has been shown to precede blast transformation and therapy resistance [3], but it is not generally accepted as a marker of acceleration (Table 2).

\section{Bone marrow fibrosis as a marker of progression}

In order to stage fibrosis, a three-tiered system has been inaugurated [4]. Myelofibrosis stage 1 reveals a loose network of reticulin with intersections, especially in peripheral areas, but no collagenisation. In stage 2, diffuse increase in reticulin with extensive intersections and only focal bundles of collagen occur. When a diffuse and dense reticulin meshwork with extensive intersections with course bundles of collagen and significant osteosclerosis are present, the criteria for stage 3 are fulfilled [4] (Table 3). Typical examples for the different stages of myelofibrosis are depicted in Fig. 1.

Medullary fibrosis has negative prognostic impact not only in CML but also in myelodysplastic syndrome (MDS) [5]. It is not a specific feature of bcr-abl-negative MPN, but these diseases exhibit an intrinsic tendency to develop myelofibrosis. Some of the MPN, like ET, do only rarely progress to myelofibrosis. Besides PMF, post-PV and postET myelofibroses have been proposed as nomenclature to describe the fibrotic progression of MPN [6]. Despite its suggestive name, PMF does not generally show evolvement to full-blown fibrosis. The latter may remain on a low level for years or may not develop at all. In a study on $102 \mathrm{PMF}$ patients with up to seven follow-up biopsies, $24.4 \%$ of patients did not develop myelofibrosis during an observation period of up to 6 years [7]. The majority of patients showed increase of fibre content in the marrow. Only a minor portion progressed from stage 2 to stage 3 [7]. In a
Table 2 Acceleration and transformation in MPN

\begin{tabular}{|c|c|c|}
\hline & Acceleration & Transformation \\
\hline \multirow[t]{6}{*}{$\begin{array}{l}\text { Bcr-abl-positive } \\
\text { CML [1] }\end{array}$} & $\begin{array}{l}\text { Unresponsiveness to } \\
\text { therapy: }\end{array}$ & $\begin{array}{l}\geq 20 \% \text { blasts in the } \\
\text { bone marrow and } / \text { or } \\
\text { peripheral blood }\end{array}$ \\
\hline & $\begin{array}{l}\text {-Persistent or increasing } \\
\text { WBC }>1 \times 105 / \mu \mathrm{l} \\
\text {-Persistent or increasing } \\
\text { thrombocytosis } \\
>1 \times 106 / \mu \mathrm{l}\end{array}$ & $\begin{array}{l}\text { Extramedullary blast } \\
\text { proliferation }\end{array}$ \\
\hline & $\begin{array}{l}\text {-Persistent or increasing } \\
\text { splenomegaly }\end{array}$ & \\
\hline & $\begin{array}{l}\text { Thrombocytopenia } \\
<1 \times 105 / \mu 1\end{array}$ & \\
\hline & $\geq 20 \%$ blood basophils & \\
\hline & $\begin{array}{l}10-19 \% \text { blasts in the } \\
\text { bone marrow and/or } \\
\text { peripheral blood }\end{array}$ & \\
\hline \multirow[t]{2}{*}{ PV } & $\begin{array}{l}\text { PMF-like (spent phase): } \\
\text { Leucoerythroblastic } \\
\text { blood smear } \\
\text {-Bone marrow fibrosis }\end{array}$ & $\begin{array}{l}\geq 20 \% \text { blasts in the } \\
\text { bone marrow and } / \text { or } \\
\text { peripheral blood }\end{array}$ \\
\hline & $\begin{array}{l}\text {-Decreasing blood cell } \\
\text { counts and increasing } \\
\text { splenomegaly } \\
\text { MDS/MPN-like: } \\
\text {-aCML } \\
\text {-CMMoL } \\
\text { Blast increase: } \\
\text {-10-19\% blasts in the } \\
\text { bone marrow and/or } \\
\text { peripheral blood }\end{array}$ & $\begin{array}{l}\text { Extramedullary blast } \\
\text { proliferation }\end{array}$ \\
\hline \multirow[t]{2}{*}{$\mathrm{PMF} / \mathrm{ET}$} & $\begin{array}{l}\text { Stage } 3 \text { myelofibrosis/ } \\
\text { osteoclerosis with } \\
\text { high clinical risk } \\
\text { scores } \\
\text { MDS/MPN-like: }\end{array}$ & $\begin{array}{l}\geq 20 \% \text { blasts in the } \\
\text { bone marrow and } / \text { or } \\
\text { peripheral blood }\end{array}$ \\
\hline & $\begin{array}{l}\text {-MDS/MPN uc } \\
\text { Blast increase: } \\
\text {-10-19\% blasts in the } \\
\text { bone marrow and/or } \\
\text { peripheral blood }\end{array}$ & $\begin{array}{l}\text { Extramedullary blast } \\
\text { proliferation }\end{array}$ \\
\hline
\end{tabular}

small subgroup, reduction of fibre content not related to therapy occurred (Table 4). The concept of obligatory progression to myelofibrosis in PMF starting from a prefibrotic stage has been developed by Thiele and coworkers [8] and was recently questioned by others, who found fibrosis also in ET [9].

Progressing myelofibrosis in MPN is associated with alterations of the haematologic and clinical status. A leucoerythroblastic blood picture usually occurs in fibrosis stages 2 and 3, and it is generally lacking when no fibrosis is present [7]. With increasing bone marrow fibrosis, thrombocyte counts normalize, or even thrombocytopenia 
Table 3 Staging of myelofibrosis in MPN

\begin{tabular}{llll}
\hline Myelofibrosis & MF 1 & MF 2 & MF 3 \\
\hline Description & $\begin{array}{c}\text { Loose network of reticulin } \\
\text { with intersections, especially } \\
\text { in peripheral areas, no } \\
\text { collagenization }\end{array}$ & $\begin{array}{l}\text { Diffuse increase in reticulin } \\
\text { with extensive intersections } \\
\text { and only focal bundles of collagen. }\end{array}$ & $\begin{array}{c}\text { Diffuse and dense increased reticulin } \\
\text { with extensive intersections with } \\
\text { course bundles of collagen and } \\
\text { significant osteosclerosis }\end{array}$ \\
Fibres & Reticulin & Hypercellular bone marrow & Mostly collagen \\
Spread & Focal, patchy & Diffulin plus collagen & Diffuse meshwork, scarring \\
Sinus & - & Sclerosis & Fibrosis, dilatation \\
Sinusoidal haematopoiesis & - & May be present & Prominent \\
Endophytic bone formation & - & May be present & Scant to prominent
\end{tabular}

occurs, and anaemia worsens. Leucocyte counts usually stay elevated. Splenomegaly also parallels the stage of myelofibrosis $[7,8]$.

Despite these clinical-pathologic correlations, myelofibrosis is not taken into account when clinical risk scores for assessment of prognosis are considered. It has been shown that the median survival with supportive therapy depends on several factors such as haemoglobin concentration $(<10 \mathrm{~g} / \mathrm{dL})$, leucocyte counts, thrombocyte counts, blasts in the peripheral blood, the karyotype and B symptoms [10-13] (Table 5). The development of myelo- fibrosis does not correlate with the JAK2 allele burden [14] and cannot be linked to particular molecular features at present.

\section{Phenotypic transitions indicating acceleration}

After a long duration, PV can undergo phenotypic changes which mimic either myelofibrosis or MDS/MPN. In the case of myelofibrotic progression, late-stage PV resembles fibrotic PMF with splenomegaly and anaemia. Fibrotic

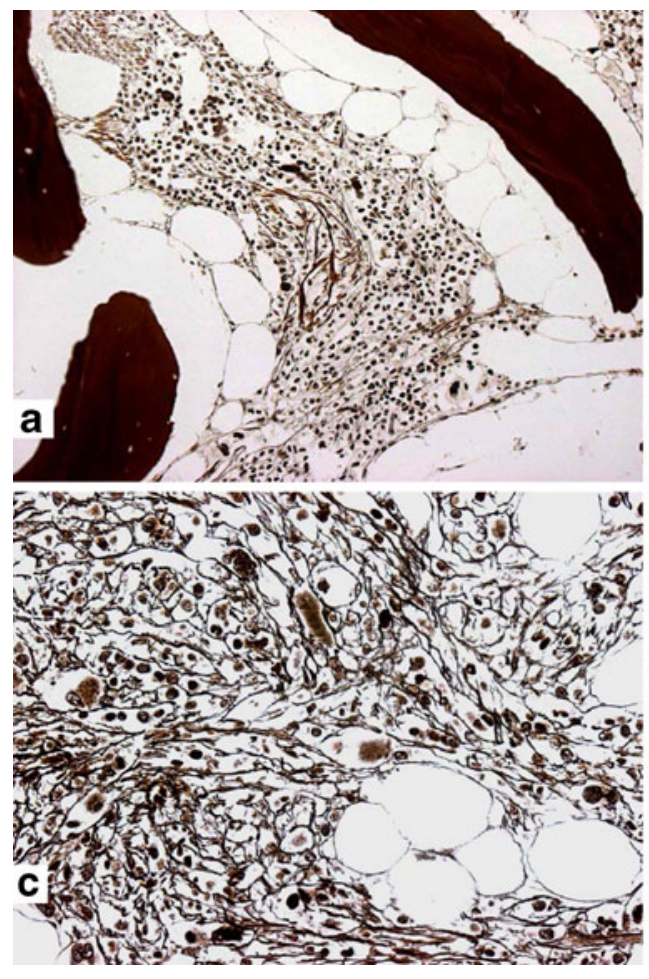

Fig. 1 Different stages of bone marrow fibrosis. In stage 1, there is only focal and loose increase of reticulin fibres, without collagenisation (a). In stage 2, reticulin fibres are diffusely increased with extensive intersections. A few bundles of collagen may be present (b, c). In stage 3, a diffuse and dense intensively intersecting reticulin

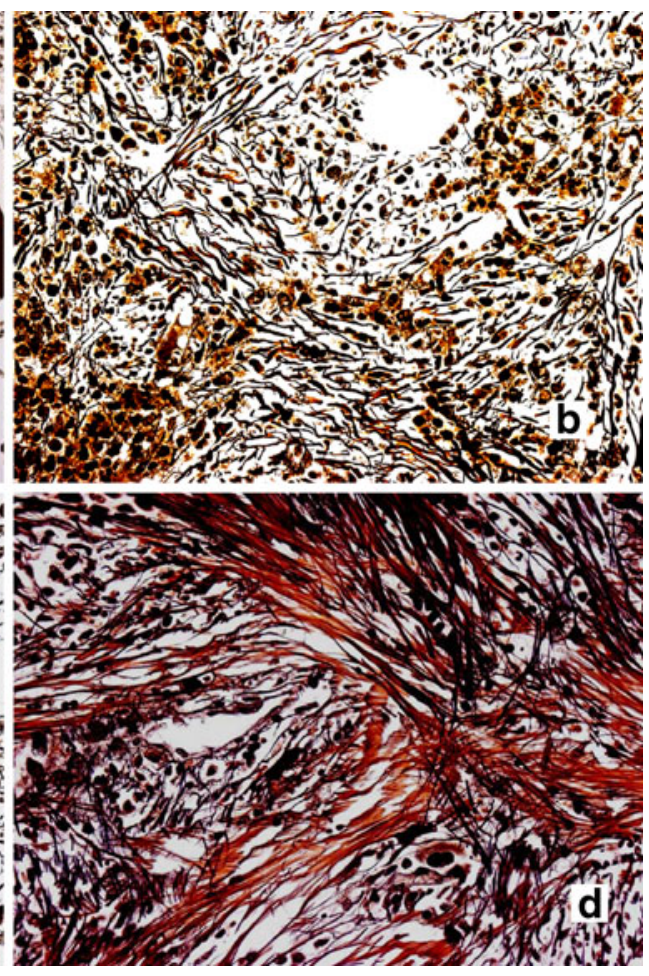

meshwork is combined with course bundles of collagen and significant osteosclerosis. In Gomori silver stain, collagen reveals a brownish appearance (d). Collagen might also be highlighted by its birefringence 
Table 4 Progression of myelofibrosis in a series of follow-up biopsies in primary myelofibrosis [7]

\begin{tabular}{lccc}
\hline $\begin{array}{l}\text { Initial fibrosis } \\
\text { staging }\end{array}$ & $\begin{array}{l}\text { No change } \\
\text { ratio (\%) }\end{array}$ & $\begin{array}{l}\text { Increase } \\
\text { ratio (\%) }\end{array}$ & $\begin{array}{l}\text { Decrease } \\
\text { ratio (\%) }\end{array}$ \\
\hline MF 0 & $11 / 31(35.5)$ & $20 / 31(64.5)$ & $0(0)$ \\
MF 1 & $7 / 24(29.2)$ & $15 / 24(62.5)$ & $2 / 24(8.3)$ \\
MF 2 & $10 / 18(55.6)$ & $6 / 18(33.3)$ & $2 / 18(11.1)$ \\
MF 3 & $11 / 12(91.7)$ & $0(0)$ & $1 / 12(8.3)$ \\
Total & $39 / 85(45.9)$ & $43 / 85(50.6)$ & $5 / 85(5.9)$ \\
\hline
\end{tabular}

transition in PV has been labelled "spent phase" or post-PV myelofibrosis [1, 6, 15]. As an alternative mode of progression, PV can evolve to proliferative states which resemble MDS/MPN, in particular bcr-abl-negative CML and chronic myelomonocytic leukaemia (CMMoL).

In Fig. 2, a case of a 66-year-old male is shown, who was known to have PV for 25 years and was treated with hydroxyurea. At the time of bone marrow biopsy, he had an elevated leucocyte count of $84 \times 10^{9} / 1$, basophilia $\left(1.4 \times 10^{9} / 1\right)$ and immature precursors in the peripheral blood. The presentation resembled CML, but no bcr-abl rearrangement was detectable, whereas $85 \%$ of $\mathrm{JAK} 2^{\mathrm{V} 617 \mathrm{~F}}$ alleles were present. Similar cases have been described by others [1619]. Besides bcr-abl-negative CML, transitions with Philadelphia chromosome positivity have been reported [20-23]. With regard to the co-existence between bcr-abl-positive and
JAK2-mutated diseases, it is likely that two independent stem cell clones proliferate in parallel [24]. Only rarely, a progression of PV can be observed which resembles CMMoL (Fig. 3).

Phenotypic transition in PMF resembles MDS/MPN with myelofibrosis. In particular, megakaryocytes reveal a different phenotype and those found in MDS. In contrast to the megakaryocytes found in the chronic phase of the disease with large cloud-like nuclei and a broad rim of cytoplasm, megakaryocytes in these cases are small with hypolobulated and small nuclei. Still, cluster formation can be observed (Fig. 4). This effect can, however, also be mimicked by hydroxyurea treatment. Usually, the phenotypic transition from PMF to MDS/MPN with fibrosis is accompanied by thrombocytopenia.

With the acquisition of MDS-like properties, the likelihood of blast increase in the bone marrow increases. An accelerated stage is diagnosed when more than $10 \%$ but less than $20 \%$ blasts are present. Immunohistochemical staining may be useful to detect blasts (Fig. 5). As a caveat, it has to be kept in mind that blasts may be CD34 negative (Fig. 5). In addition, dysplastic megakaryocytes display a spectrum of maturation, and some more mature forms may also be labelled, which cannot be considered as blasts (Fig. 5). Because a try tap is frequent in progressed PMF, bone marrow smears may not be available, and blast determination may completely rest on their morphological identification in CD34-negative cases.

Table 5 Risk scores in primary myelofibrosis

\begin{tabular}{|c|c|c|c|c|}
\hline & Lille Score [8] & DIPSS plus Score [9] & International Score [10] & Mayo Score [11] \\
\hline Haemoglobin & $<10 \mathrm{~g} / \mathrm{dL}$ & $<10 \mathrm{~g} / \mathrm{dL}$ & $<10 \mathrm{~g} / \mathrm{dL}$ & $<10 \mathrm{~g} / \mathrm{dL}$ \\
\hline Leucocytes & $<4$ or $>30 \mathrm{G} / \mathrm{L}$ & - & $>25 \mathrm{G} / \mathrm{L}$ & $<4$ or $>30 \mathrm{G} / \mathrm{L}$ \\
\hline Blasts in peripheral blood & - & $\geq 1 \%$ & $\geq 1 \%$ & - \\
\hline Thrombocyte count & - & $<100 \mathrm{G} / \mathrm{L}$ & - & $<100 \mathrm{G} / \mathrm{L}$ \\
\hline Monocyte count & - & - & - & $>1 \mathrm{G} / \mathrm{L}$ \\
\hline Constitutional symptoms & - & + & + & - \\
\hline Red cell transfusion need & & + & & \\
\hline Age & - & $>65$ years & $>65$ years & - \\
\hline Cytogenetic aberrations & - & $\begin{array}{l}\text { Complex karyotype or sole or } \\
\text { two abnormalities that include } \\
+8,-7 / 7 \mathrm{q}-, \mathrm{i}(17 \mathrm{q}),-5 / 5 \mathrm{q}-, 12 \mathrm{p}- \\
\text { inv(3), or } 11 \mathrm{q} 23 \text { rearrangement }\end{array}$ & $\begin{array}{l}\text { Only in intermediate risk, } \\
\text { when combined with } \\
\text { anaemia }\end{array}$ & - \\
\hline Score, low & 0 & 0 & 0 & 0 \\
\hline Score, intermediate & 1 & $1,2-3$ & 1,2 & 1 \\
\hline Score, high & 2 & $\geq 4$ & $\geq 3$ & $\geq 2$ \\
\hline Median survival, low risk (months) & 93 & 180 & 135 & 173 \\
\hline $\begin{array}{l}\text { Median survival, intermediate } \\
\text { risk (months) }\end{array}$ & 26 & $\begin{array}{l}\text { Intermediate } 1,63 \\
\text { Intermediate } 2,33\end{array}$ & $\begin{array}{l}\text { Intermediate } 1,95 \\
\text { Intermediate } 2,48\end{array}$ & 61 \\
\hline Median survival, high risk (months) & 13 & 16 & 27 & 26 \\
\hline
\end{tabular}




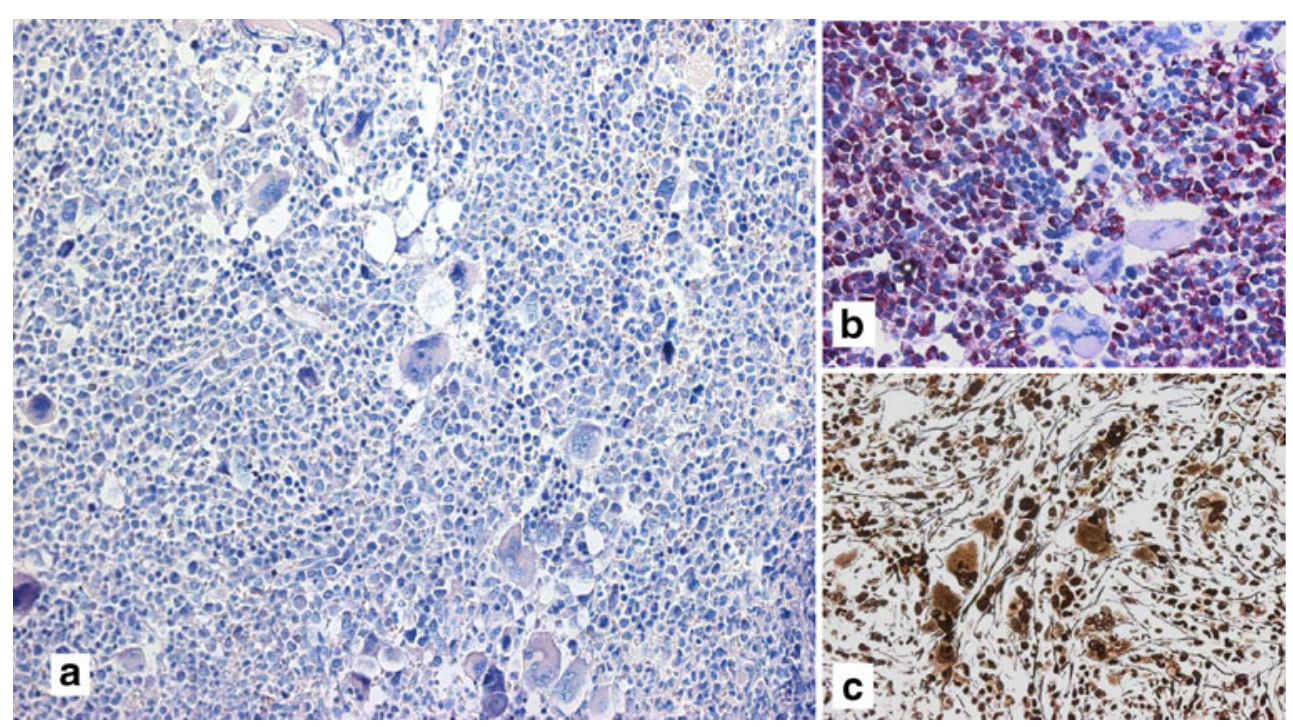

Fig. 2 Atypical CML-like acceleration in a case of PV. After 25 years of PV treated with phlebotomy and hydroxyurea, a 66-year-old male presented with a leucocyte count of $84 \times 10^{9} / 1$; basophils, $1.428 \times 10^{9} / 1$; pathologic left shift; erythrocytes, $6.85 \times 10^{12} / 1$; haemoglobin, $17.1 \mathrm{~g} / \mathrm{dll}$; thrombocytes, $573 \times 10^{9} / 1$; LDH, 1,362 U/1 and spleen enlargement.
JAK2 $2^{\mathrm{V} 617 \mathrm{~F}}$ was found in $85 \%$ of alleles, and bcr-abl was negative. Bone marrow biopsy revealed a relative reduction of erythropoiesis and a tremendous increase of granulopoiesis (a). Increased granulopoiesis is highlighted by chloroacetate esterase staining (b). There was slight increase of reticulin fibres (c)

\section{Transformation to blast crisis}

In contrast to bcr-abl-positive CML, blast transformation in $\mathrm{PV}, \mathrm{PMF}$ and ET is less frequent and provides a rather late event, occurring after many years of disease duration. The diagnosis of blast transformation rests on the demonstration of $\geq 20 \%$ blasts in the bone marrow or peripheral blood. Alternatively, an extramedullary blast infiltration is considered to represent transformation.

Blast crisis in PV, PMF and ET usually reveals a myelomonocytic or myeloid phenotype (Fig. 6). Only rarely does a lymphoblastic phenotype occur [25]. The blast infiltration in the bone marrow appears diffuse in most instances. Sometimes, focal and nodular infiltrates can be seen (Fig. 6). A blast crisis may be the result of clonal evolution which is obvious from a complex karyotype (Fig. 7). The phenotypic transition to an MDS/MPN phenotype preceding transformation often is paralleled by the development of a complex karyotype which is typical for secondary AML (Figs. 6d, 7). In other cases, a cytogenetic study does not reveal any abnormalities, and the persisting megakaryocytes still exhibit the typical PMF morphology (Fig. 6c).

Interestingly, in a considerable proportion of cases, the JAK2 mutation is lacking in the blast cells. Therefore,
Fig. 3 Progression to a CMMoL-like MDS/MPN in a case of PV. A 76-year-old male with a long duration of PV and erythrocyte count of $6.3 \times$ $10^{12} / 1$; leucocytes, $22 \times 10^{9} / 1$; thrombocytes, $283 \times 10^{9} / 1$ and an enlarged spleen $(16 \times 7 \mathrm{~cm})$ showed monocytosis in the peripheral blood $\left(5.940 \times 10^{9} / 1\right)$. Bone marrow smears (a) as well as histology (b) revealed an increase of monocytes like in CMMoL. JAK2 ${ }^{\mathrm{V} 617 \mathrm{~F}}$ was present in $18 \%$ of alleles. A wild type was found for CBL and $\mathrm{N}$-ras, respectively, and bcr-abl was negative

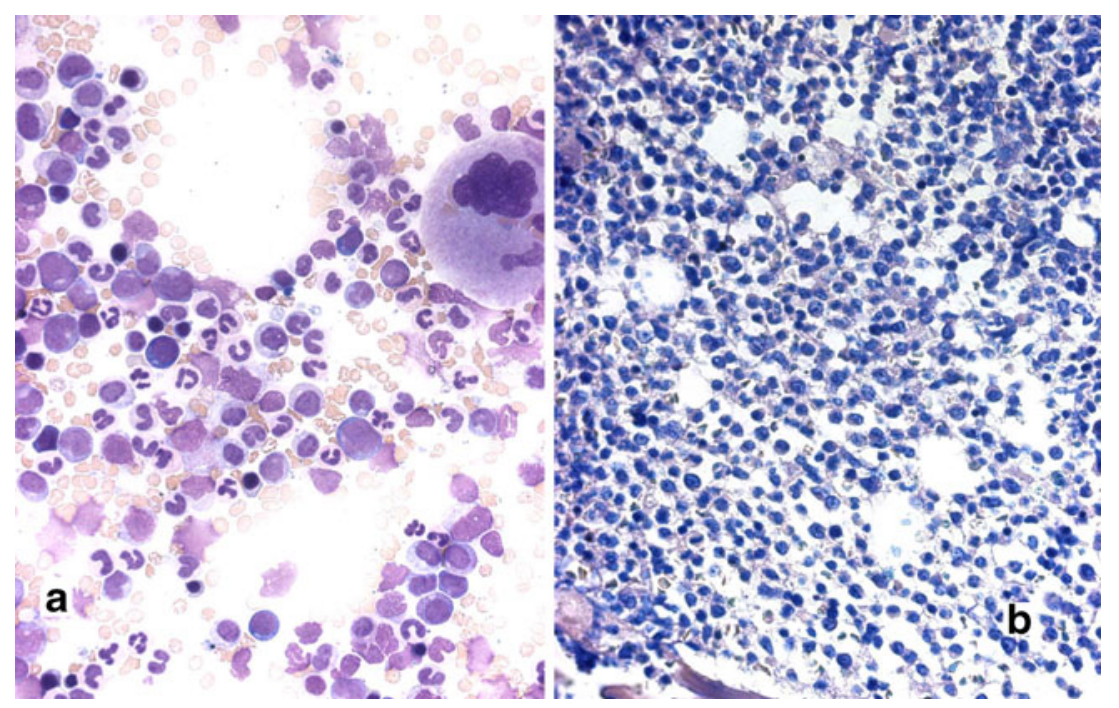


Fig. 4 PMF with MDS/MPNlike features during acceleration. Many PMF cases progress from thrombocytosis to thrombocytopenia. This may be accompanied by the appearance of MDS-like features. Megakaryocytes are hypolobulated and dysplastic as in MDS and do not resemble the large variants usually found in PMF (a, b). CD42 immunohistochemistry decorates atypical megakaryocytes which still show increased formation of prothrombocytes (c). Usually there is prominent myelofibrosis (d)

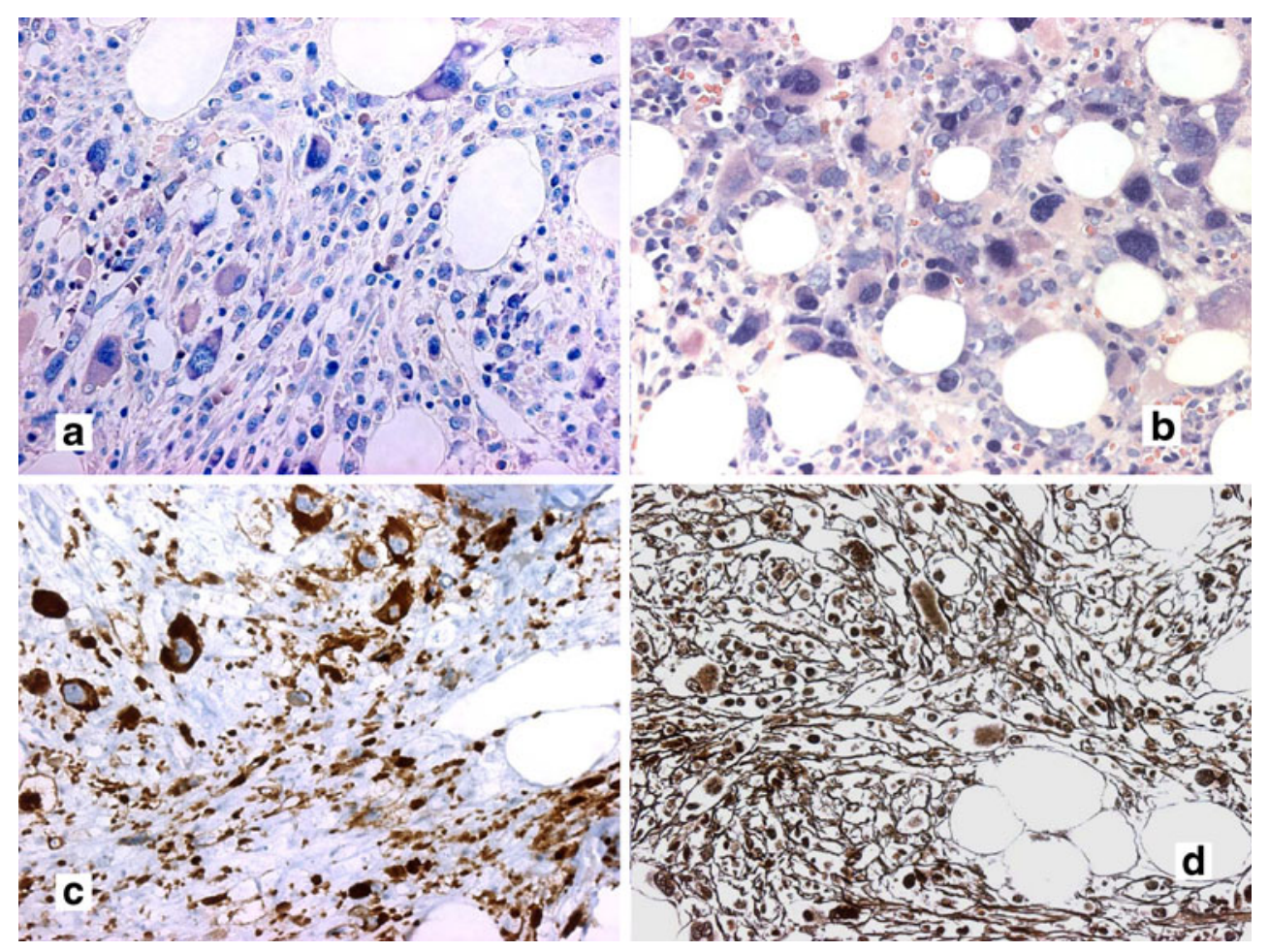

different routes to leukaemic transformation in JAK2mutated MPN have been suggested [26]. Blast crisis may evolve from an independent hematopoietic stem cell clone, which is not related to the JAK2 or MPL mutated clone. Second, the MPN and blast clone may have a common ancestor with a shared mutation, e.g. of the TET2 gene. The third scenario of blast progression in MPN resembles that of CML with clonal evolution of blasts from the JAK2 or MPL mutated stem cell clone [26]. Loss of JAK2 $2^{\mathrm{V} 617 \mathrm{~F}}$ mutation due to mitotic recombination could also be possible but was
Fig. 5 CD34 stain for blasts in MPN. CD34 may be helpful in detecting and quantifying blasts in the bone marrow of accelerating MPN (a). However, care has to be taken that micromegakaryocytes and normal megakaryocytes may also be labelled by anti-CD34 staining (b). In cases as shown in (b), a more or less arbitrary discrimination has to be made when CD34 blasts are quantified. Furthermore, in MPN, unambiguous blasts by morphology (c) may be completely negative for CD34 (d)
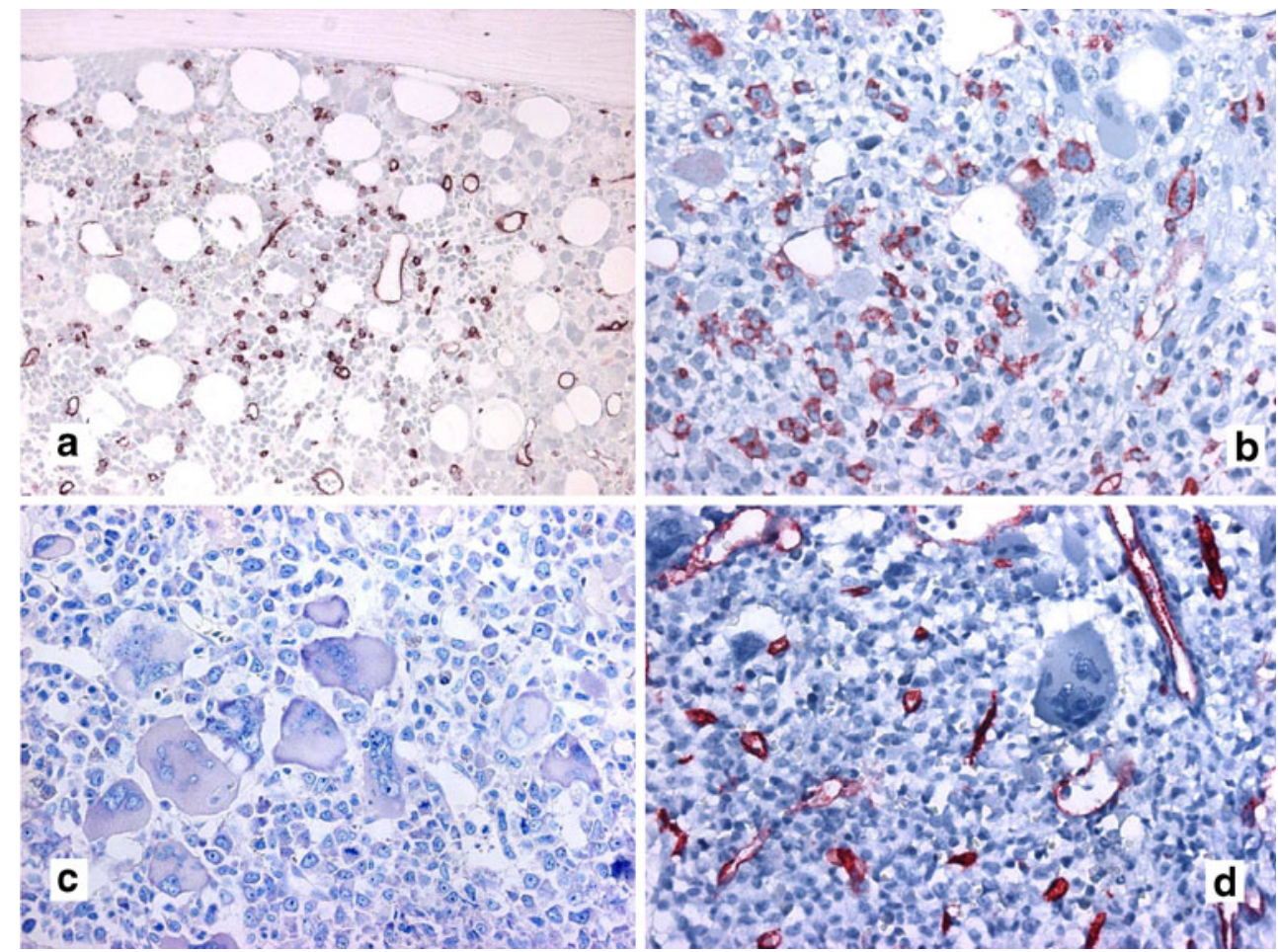
Fig. 6 Transformation to AML in MPN. Blast infiltrates may be diffuse with complete effacement of haematopoiesis (a). Alternatively, the blast increase may be focal with persisting maturing haematopoiesis outside of the blast infiltrates, which might escape cytologic detection (b). Blast crisis may be manifest already at presentation with high thrombocyte counts, no fibrosis and large megakaryocytes typical for PMF (c). In contrast, d shows a blast crisis which develops in progressed myelofibrosis with dysplastic megakaryocytes with MDS-like features. Most blast crises display a myelomonocytic phenotype as shown in (e) where focal CD68positive blast infiltrates are shown. The blasts in (a) were negative for Jak2 V617F which was, however, found in the preceding MPN

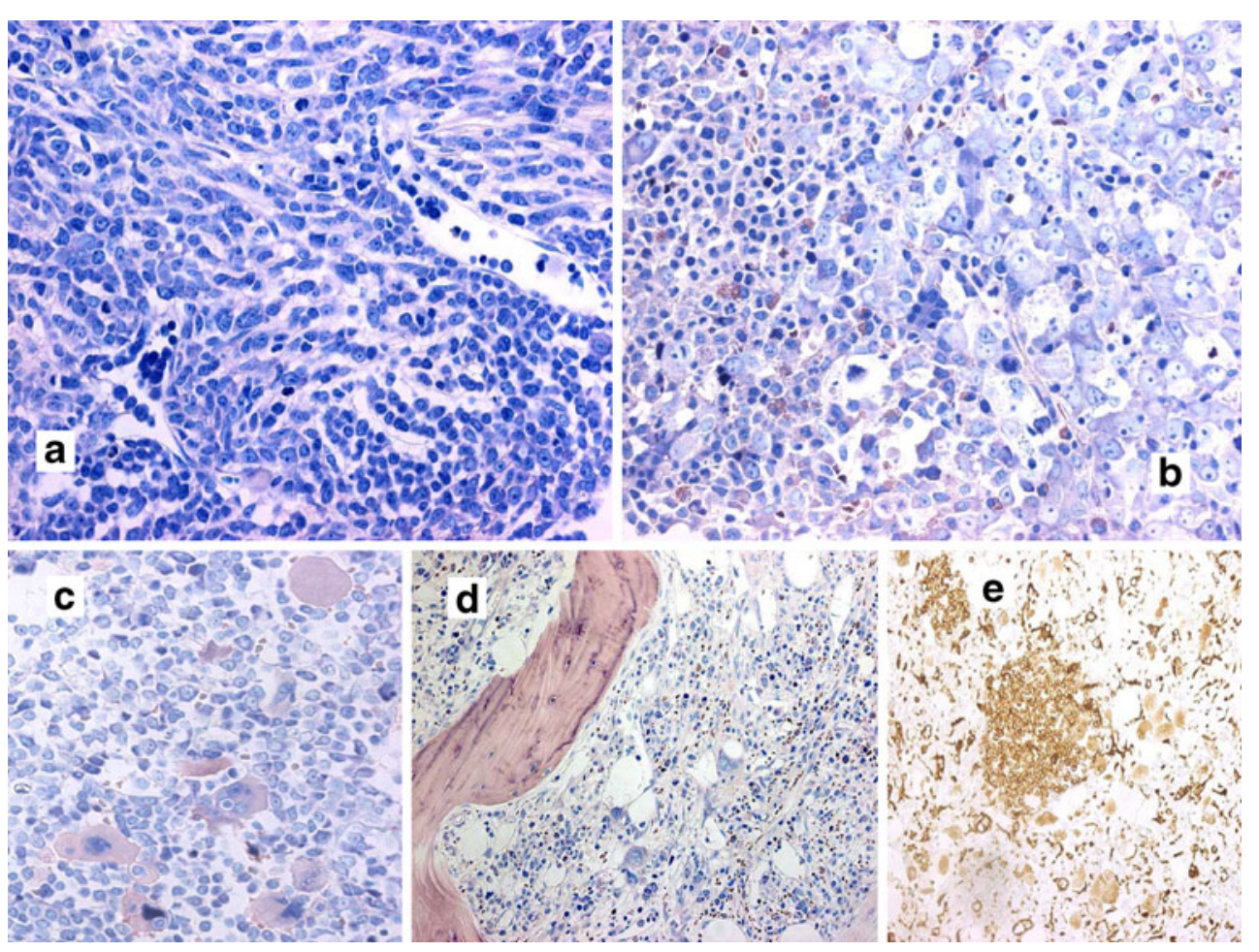

not found in a series of blast crisis [26]. Aberrations which discriminate the chronic from the acute phase of MPN affect the genes for WT1, p53, CBL, N-ras, TET2, as well as IDH1 and IDH2 $[26,27]$ indicating a potential role in clonal evolution. Chromosomal gains and losses were found with a threefold higher frequency in the blast phase in comparison to the chronic phase [28]. Besides trisomy 8 , losses of $7 q$ and $17 \mathrm{p}$ were observed [18]. Altered chromosomal regions were found on 16q, 19p and 21q [28]. Obviously, blast progression in MPN is the result of a number of different genetic events during clonal evolution. At present, it is not possible to sort out which of the aberrations can be linked to genotoxic therapy such as hydroxyurea, which is commonly applied in MPN. Because AML also occurs in treatmentnaive patients [15], there is little doubt that blast progression belongs to the natural history of MPN.

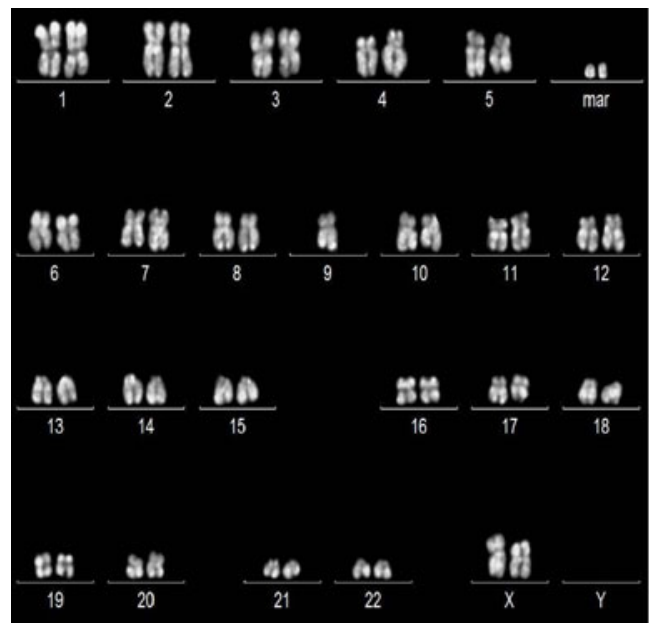

Fig. 7 Karyotypic evolution in a case of ET progressing to blast crisis. A complex karyotype was seen in a 55-year-old male who was diagnosed with ET 12 years ago. He had acquired pancytopenia, and the corresponding bone marrow trephine is shown in Fig. 6d. At presentation, no aberrations were present. The complex karyotype could

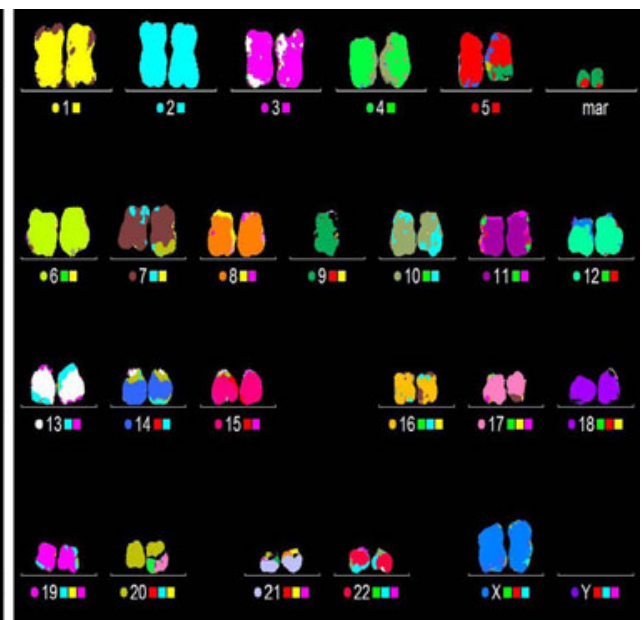

be resolved by chromosomal painting as: $45 \sim 47, \mathrm{XX}$, $\operatorname{der}(5) \mathrm{t}(5 ; 9)(\mathrm{q} 14$; $\mathrm{q}$ ?), $\mathrm{t}(7 ; 17 ; 20)(\mathrm{q} 31 ; \mathrm{q} 22 ; \mathrm{q} 12),-9,+1-2 \operatorname{mar}[\mathrm{cp} 19] / 46, X X[1]$.nuc ish 5p15.2(5p15.2x2), 5q31(EGR1x1[85/100], $\operatorname{cen} 7($ CEP7 2 2), $7 \mathrm{q} 31$ (D7S486x2). 11q23(MLLx2),12p13(TELx2),20q12(D20S108x2)[100] 
Conflict of interest The authors declare that they have no conflict of interest.

\section{References}

1. Swerdlow SH, Campo E, Harris NL, Jaffe SS, Pileri SA, Stein H, Thiele J, Vardiman JW (2008) WHO classification of tumours of haematopoietic and lymphoid tissues. IARC, Lyon

2. Campbell PJ, Green AR (2006) The myeloproliferative disorders. N Engl J Med 355:2452-2466

3. Buesche G, Ganser A, Schlegelberger B, von Neuhoff N, Gadzicki D, Hecker H, Bock O, Frye B, Kreipe H (2007) Marrow fibrosis and its relevance during imatinib treatment of chronic myeloid leukemia. Leukemia 21:2420-2427

4. Thiele J, Kvasnicka HM, Facchetti F, Franco V, van der Walt J, Orazi A (2005) European consensus on grading bone marrow fibrosis and assessment of cellularity. Haematologica 90:11281132

5. Buesche G, Teoman H, Wilczak W, Ganser A, Hecker H, Wilkens L, Göhring G, Schlegelberger B, Bock O, Georgii A, Kreipe H (2008) Marrow fibrosis predicts early fatal marrow failure in patients with myelodysplastic syndromes. Leukemia 22:313-322

6. Mesa RA, Verstovsek S, Cervantes F, Barosi G, Reilly JT, Dupriez B, Levine R, Le Bousse-Kerdiles MC, Wadleigh M, Campbell PJ, Silver RT, Vannucchi AM, Deeg HJ, Gisslinger H, Thomas D, Odenike O, Solberg LA, Gotlib J, Hexner E, Nimer SD, Kantarjian H, Orazi A, Vardiman JW, Thiele J, International Working Group for Myelofibrosis Research and Treatment (IWGMRT) (2007) Primary myelofibrosis (PMF), post polycythemia vera myelofibrosis (post-PV MF), post essential thrombocythemia myelofibrosis (post-ET MF), blast phase PMF (PMF-BP): consensus on terminology by the international working group for myelofibrosis research and treatment (IWG-MRT). Leuk Res 31:737-740

7. Buhr T, Büsche G, Choritz H, Länger F, Kreipe H (2003) Evolution of myelofibrosis in chronic idiopathic myelofibrosis as evidenced in sequential bone marrow biopsy specimens. Am J Clin Pathol 119:152-158

8. Thiele J, Kvasnicka HM (2003) Diagnostic differentiation of essential thrombocythaemia from thrombocythaemias associated with chronic idiopathic myelofibrosis by discriminate analysis of bone marrow features-a clinicopathological study on 272 patients. Histol Histopathol 18:93-102

9. Campbell PJ, Bareford D, Erber WN, Wilkins BS, Wright P, Buck G, Wheatley K, Harrison CN, Green AR (2009) Reticulin accumulation in essential thrombocythemia: prognostic significance and relationship to therapy. J Clin Oncol 27:2991-2999

10. Dupriez B, Morel P, Demory JL, Lai JL, Simon M, Plantier I, Bauters F (1996) Prognostic factors in agnogenic myeloid metaplasia: a report on 195 cases with a new scoring system. Blood 88:1013-1018

11. Gangat N, Caramazza D, Vaidya R, George G, Begna K, Schwager S, Van Dyke D, Hanson C, Wu W, Pardanani A, Cervantes F, Passamonti F, Tefferi A (2011) DIPSS plus: a refined Dynamic International Prognostic Scoring System for primary myelofibrosis that incorporates prognostic information from karyotype, platelet count, and transfusion status. J Clin Oncol 29:392-397

12. Cervantes F, Dupriez B, Pereira A, Passamonti F, Reilly JT, Morra E, Vannucchi AM, Mesa RA, Demory JL, Barosi G, Rumi E, Tefferi A (2009) New prognostic scoring system for primary myelofibrosis based on a study of the International Working Group for Myelofibrosis Research and Treatment. Blood 113:2895-2901

13. Elliott MA, Verstovsek S, Dingli D, Schwager SM, Mesa RA, Li CY, Tefferi A (2007) Monocytosis is an adverse prognostic factor for survival in younger patients with primary myelofibrosis. Leuk Res 31:1503-1509

14. Hussein K, Bock O, Theophile K, von Neuhoff N, Buhr T, Schlué J, Büsche G, Kreipe H (2009) JAK2(V617F) allele burden discriminates essential thrombocythemia from a subset of prefibrotic-stage primary myelofibrosis. Exp Hematol 37:11861193

15. Finazzi G, Caruso V, Marchioli R, Capnist G, Chisesi T, Finelli C, Gugliotta L, Landolfi R, Kutti J, Gisslinger H, Marilus R, Patrono C, Pogliani EM, Randi ML, Villegas A, Tognoni G (2005) ECLAP Investigators. Acute leukemia in polycythemia vera: an analysis of 1638 patients enrolled in a prospective observational study. Blood 105:2664-2670

16. Lugassy G, Farhi R (1989) Chronic neutrophilic leukemia associated with polycythemia vera. Am J Hematol 31:300-301

17. Iurlo A, Foa P, Maiolo AT, Luksch R, Capsoni F, Polli EE (1990) Polycythemia vera terminating in chronic neutrophilic leukemia: report of a case. Am J Hematol 35:139-140

18. Foa P, Iurlo A, Saglio G, Guerrasio A, Capsoni F, Maiolo AT (1991) Chronic neutrophilic leukaemia associated with polycythemia vera: pathogenetic implications and therapeutic approach. Br J Haematol 78:286-288

19. Higuchi T, Oba R, Endo M, Harada H, Mori H, Niikura H, Omine M, Fujita K (1999) Transition of polycythemia vera to chronic neutrophilic leukemia. Leuk Lymphoma 33:203-206

20. Hoppin EC, Lewis JP (1975) Polycythemia rubra vera progressing to Ph-positive chronic myelogenous leukemia. Ann Intern Med $83: 820-823$

21. Haq AU (1990) Transformation of polycythemia vera to $\mathrm{Ph}$ positive chronic myelogenous leukemia. Am J Hematol 35:110 113

22. Jantunen E, Nousiainen T (1991) Ph-positive chronic myelogenous leukemia evolving after polycythemia vera. Am J Hematol $37: 212$

23. Mirza I, Frantz C, Clarke G, Voth AJ, Turner R (2007) Transformation of polycythemia vera to chronic myelogenous leukemia. Arch Pathol Lab Med 131:1719-1724

24. Büsche G, Hussein K, Bock O, Kreipe H (2007) Insights into JAK2-V617F mutation in CML. Lancet Oncol 8:863-864

25. Dunphy CH, Kitchen S, Saravia O, Velasquez WS (1996) Acute myelofibrosis terminating in acute lymphoblastic leukemia: case report and review of the literature. Am J Hematol 51:85-89

26. Beer PA, Delhommeau F, LeCouédic JP, Dawson MA, Chen E, Bareford D, Kusec R, McMullin MF, Harrison CN, Vannucchi AM, Vainchenker W, Green AR (2010) Two routes to leukemic transformation after a JAK2 mutation-positive myeloproliferative neoplasm. Blood 115:2891-2900

27. Pardanani A, Lasho TL, Finke CM, Mai M, McClure RF, Tefferi A (2010) IDH1 and IDH2 mutation analysis in chronic- and blastphase myeloproliferative neoplasms. Leukemia 24:1146-1151

28. Thoennissen NH, Krug UO, Lee DH, Kawamata N, Iwanski GB, Lasho T, Weiss T, Nowak D, Koren-Michowitz M, Kato M, Sanada M, Shih LY, Nagler A, Raynaud SD, Müller-Tidow C, Mesa R, Haferlach T, Gilliland DG, Tefferi A, Ogawa S, Koeffler HP (2010) Prevalence and prognostic impact of allelic imbalances associated with leukemic transformation of Philadelphia chromosome-negative myeloproliferative neoplasms. Blood 115:2882-2890 